\title{
Self-healing of low-velocity impact and mode-I delamination damage in polymer composites via microchannels
}

\author{
M. U. Saeed ${ }^{1}$, B. B. Li $^{1}$, Z. F. Chen ${ }^{1 *}$, S. Cui ${ }^{2}$ \\ ${ }^{1}$ College of Material Science and Technology, Nanjing University of Aeronautics and Astronautics, 29 Yudao Street, \\ 210016 Nanjing, PR China \\ ${ }^{2}$ College of Materials Science and Engineering, Nanjing University of Technology, 211800 Nanjing, PR China
}

Received 1 September 2015; accepted in revised form 9 November 2015

\begin{abstract}
Microchannels embedded polymer composites were fabricated by resin infusion process using carbon fabric, epoxy resin and hollow glass tubes (HGTs). The effect of a range of low-velocity impact (LVI) and mode-I delamination (M1D) damage on the flexural strength of microchanneled carbon- epoxy composites was studied. A self-healing approach was also employed to recover their lost flexural strength due to these damages. Moreover, influence of LVI, M1D damage and healing on the failure behavior of microchanneled carbon- epoxy composites was also investigated. The results of flexural after impact (FAI) and flexural after delamination (FAD) showed that LVI has more deleterious effect on the flexural strength of carbon- epoxy composites than M1D damage. The loss in flexural strength increased linearly with increase in both impact (by higher impact energies) and delamination damage (by longer delamination lengths). Scanning electron microscopic (SEM) study revealed that self-healing agent (SHA), stored in HGTs placed within carbon- epoxy composites, effectively healed both LVI and M1D damage with excellent healing efficiencies.
\end{abstract}

Keywords: smart polymers, self-healing, low-velocity impact, delamination, polymer composites

\section{Introduction}

Due to their superior specific strength, stiffness and design flexibility, fiber reinforced polymeric (FRP) composites are widely used in numerous aerospace and engineering applications. However, their poor out-of-plane mechanical properties make them susceptible to various damages like impact, inter-ply delamination and interlaminar shear that result in performance degradation of composite structures [1-3]. Moreover, in most cases, these damages lie beneath the surface or barely visible and a lot of non-destructive (NDT) inspections are necessarily performed to seek their presence and prevent catastrophic failure of structure $[4,5]$. Consequently, large factors of safety are incorporated in design to ensure their safety and reliability, which lead to composite structures with higher weight and thicker sections. How- ever, mimic to self-healing capabilities of biological organisms, recent development of self-healing FRP composites that can heal themselves upon damage has proved to be an excellent solution to these problems [6-8].

In FRP composites, self-healing capabilities can be achieved using modified self-healable matrices, SHA-filled microcapsules and SHA-filled microchannels. In modified healable matrix systems [911], weak chemical bonds are created within matrix that preferentially breakdown upon damage and reform on heating. Microcapsule-filled healing systems [12-15] contain monomer-filled microcapsules along with solid-phase catalyst throughout the matrix, while microchannel-based healing systems [16-18] comprise SHA-filled vascular channels setin at different locations in the structure. Upon dam-

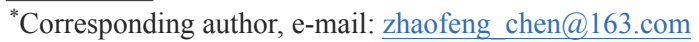

(C) BME-PT
} 
age, these chemicals react with each other to repair the damage. Among them, healing through SHAfilled microchannels are getting more and more attentions these days due to additional benefits, such as multifunctional uses for self-sensing [19], enhanced damage visualization [18, 20], active-cooling [21], continuous supply of SHA for higher number of damage-repair cycles $[22,23]$, autonomous selfhealing [24] and accelerated self-healing [25].

In the last decade or so, researchers have employed a variety of manufacturing techniques to vascularize polymeric composites [26] and have studied the effect of different damages on their mechanical properties, their healing via microvascules and restoration of strength under different loading conditions. Among them, Bleay et al. [27] placed $5 \mu \mathrm{m}$ internal diameter, hollow glass fiber (HGFs) plies within a composite laminate and then infused them with SHA for self-healing (in the cured laminate). Compression after LVI testing of their composite panels indicated limited healing due to partial access of resin to the damage area. To improve the healing efficiency, Bond and co-workers utilized $60 \mu \mathrm{m}$ HGFs and a two part epoxy resin as SHA (separately loaded). However, instead of LVI, they carried out pseudo impacts followed by flexural testing to evaluate the strength restoration after self-repair and found it significant ( 97\%) [20, 28]. Following same methodology, William et al. [29] produced self-healing carbon fiber reinforced composites (CFRC) and conducted flexural test after quasi-static impact and compression test after LVI [30] and in both cases got $>90 \%$ healing efficiency. Similarly, using millimeter scale HGFs, Zainuddin et al. [31] researched the multiple LVI properties of e-glass/epoxy composites and reported good recovery in multiple LVI properties. Moving a step ahead, Norris et al. [24] employed an autonomous healing approach (selfsense and self-heal) on CFRC and achieved 94\% recovery in compression after LVI strength. Likewise, Yue et al. [32] used SHA-filled capillaries for self-healing, but they also monitored the click chemistry in real time in an elastomer composite by dynamic mechanical analyses. They found their approach quick and versatile in restoring the storage modulus of composite. So far, researchers have either used compression test after drop-weight impact or flexural test after pseudo impact (indentation) to assess the restoration of strength due to self-healing. However, only Kling and Czigány [33] studied the self-healing in HGF reinforced composites through LVI (drop-weight) and three point bend test, but they used HGF fabric. Besides, these studies on healing and restoration of mechanical strength after impact, Kessler and White [34] have studied the healing of delamination damage via restoration of mode-I fracture toughness. However, instead of SHA-filled microchannels, they either directly injected the SHA in the delamination crack or employed SHA-filled microcapsules [35]. Whereas, Patrick et al. [36] have studied the restoration of mode-I fracture toughness through healing of delamination damage via vascular network. Therefore, more research is needed to evaluate the effect and healing of LVI (by dropweight) and delamination damage (by mode-I loading) on CFRC under different loading conditions.

This study investigates the self-healing of LVI (by drop-weight) and delamination damage (by mode-I loading) in microchanneled carbon-epoxy composites by employing four-point-flexural after impact/ delamination protocol and SHA-filled microchannels. The effect of healing on the flexural failure of undamaged, LVI-damaged and M1D-damaged microchanneled carbon-epoxy composites is also studied. In this research a novel scheme has also been devised and adopted for the self-activation of self-healing upon mode-1 delamination damage. Microchanneled carbon-epoxy composites samples for M1D were designed and manufactured in such a way that HGTs with variable lengths were carefully placed at specific distances from the Polytetrafluoroethylene (PTFE) film. So, when a mode-I tensile load was applied on the sample, the M1D was generated and during its growth at the specific distance, it hit the circular edge of SHA-filled HGT to release SHA for self-healing.

\section{Experimental \\ 2.1. Materials}

Carbon fabric (CF3011) used in this study was produced by Weihai Tuozhan Fiber Co. Ltd, China and two-part epoxy resin (Resin-GCC135/HardenerW93) were purchased from Kunshan Chemicals, China. Whereas, Hollow glass tubes (HGTs) were obtained from Huaxi University, China. Carbon fabric was used as reinforcement and two-part epoxy resin was used as matrix as well as SHA with 100:30; Resin-Hardener ratio. The carbon fibers were PAN based having $3550 \mathrm{MPa}$ tensile strength, $230 \mathrm{GPa}$ tensile modulus, 3000 filaments in one 
bundle. Carbon fabric was plain weaved having $200 \mathrm{~g} \cdot \mathrm{m}^{-2}$ aerial weight. The epoxy resin was Bisphenolic-A based with a viscosity of $700-1100 \mathrm{mPa} \cdot \mathrm{s}$ and curing cycle of 24 hours at $25^{\circ} \mathrm{C}$. HGTs with $0.9 \mathrm{~mm}$ internal diameter were inserted in carbonepoxy composites to create microchannels.

\subsection{Preparation of microchanneled carbon- epoxy composites}

A dry layered-preform was prepared by placing an array of HGTs in the longitudinal direction (with sealed ends) at the mid-plane of carbon fabric layers upon a polished mold surface. Then peel ply, flow media, spiral tubing and resin in-out pipes were positioned accordingly and whole assembly was sealed using Capron film and tacky tape. A vacuum pump was then connected through reservoir to suck-out all the air present inside the bag and among layers. Room temperature cured, low-viscosity epoxy resin was then infused to fill up the vacuum cavities among carbon fabric layers. After curing, microchanneled carbon-epoxy composite laminate was de-molded, peel ply was removed and laminate edges were trimmed to expose the edge faces of HGTs. Schematic diagram of the process is shown in Figure 1.

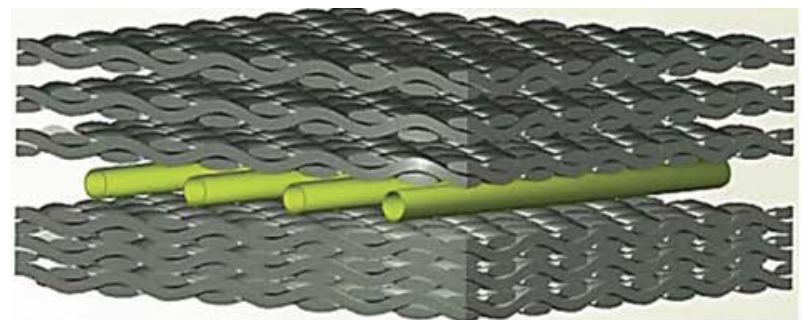

$(a-i)$

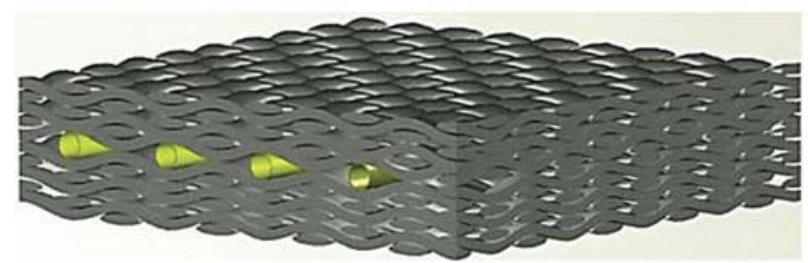

(b-i)

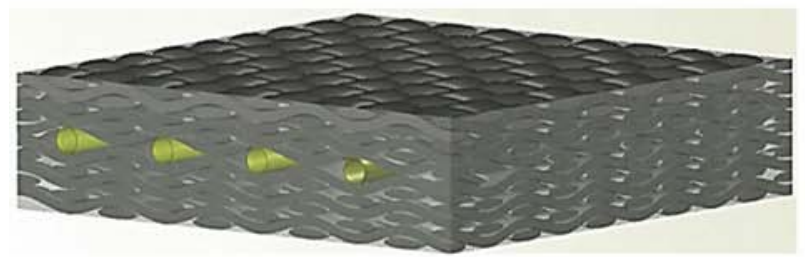

(c-i)
Two similar composite sheets with HGTs were prepared, one for flexural after LVI (FAI) and other for flexural after M1D (FAD) testing. The second sheet was slightly different from the first. In it, a $15 \mu \mathrm{m}$ thick PTFE film was used at the mid-plane to generate the starter crack. Additionally, HGTs with lengths $60,65,70$ and $75 \mathrm{~mm}$ were carefully placed at 20 , 15,10 and $5 \mathrm{~mm}$ distances from the PTFE film respectively to generate four different sets of samples. Piano hinges were bonded to the samples for load transmission. The thin and long edges of the samples were coated with white corrector fluid and scaled for every $2.5 \mathrm{~mm}$ length to visually observe and measure the delamination crack length [37]. Nominal dimensions of M1D samples were; length $l=150 \mathrm{~mm}$, width $b=25 \mathrm{~mm}$ and starter crack length $a_{0}=50 \mathrm{~mm}$. While dimensions of FAD, LVI and FAI samples were length $l=80 \mathrm{~mm}$, width $b=25 \mathrm{~mm}$ as shown in Figure 2. Samples for LVI, M1D and FAD were cut from their respective laminate sheets. Separate sample IDs of FAI4, FAI6, FAI9, FAI11 and FAD5, FAD10, FAD15, FAD20 were assigned to each set of samples. Where FAI represented flexural after impact, 4, 6, 9, 11 were the impact energies with 4, 6, 9, $11 \mathrm{~J}$, FAD for flexural after delam-

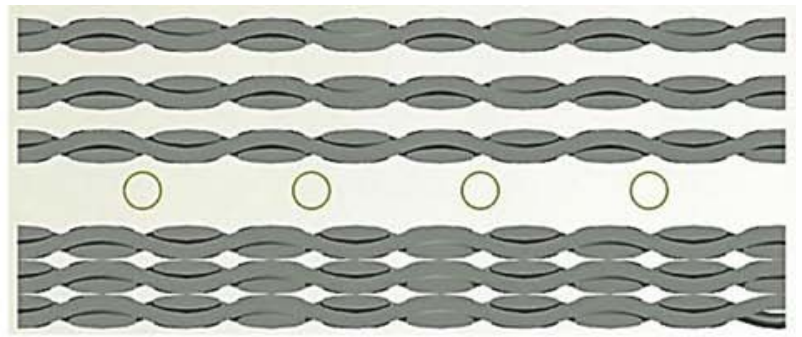

(a-ii)

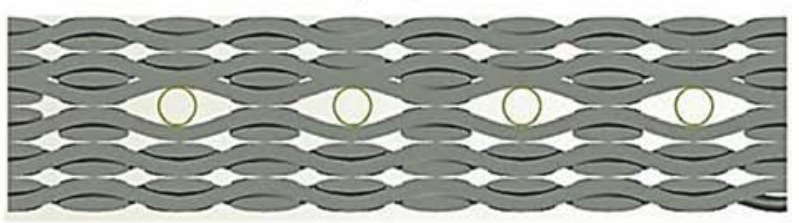

(b-ii)

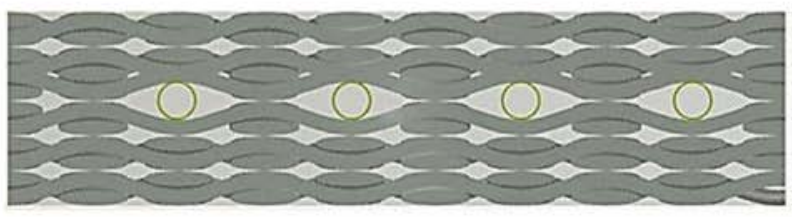

(c-ii)

Figure 1. Preparation of microchanneled carbon- epoxy composites; (a-i and a-ii) placement of HGTs between dry fabric layers, (b-i and b-ii) composite processing by resin infusion and (c-i and c-ii) cured microchanneled carbon/ epoxy composite 


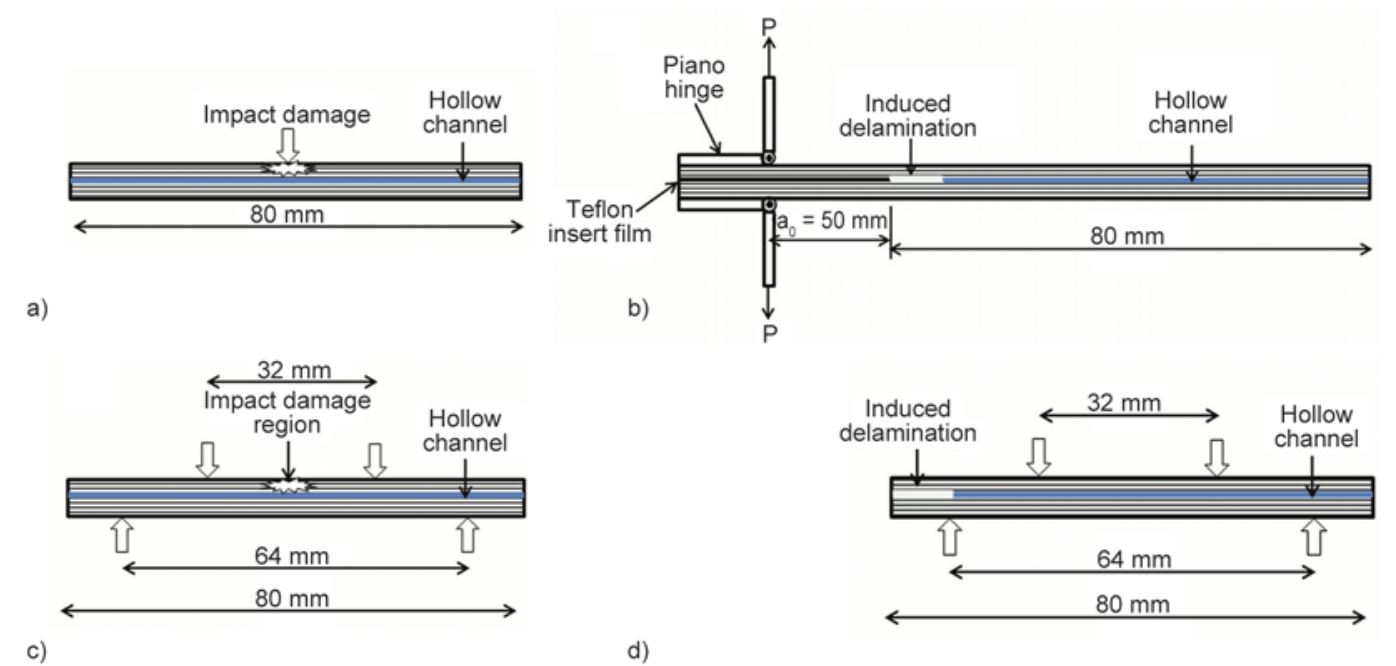

Figure 2. Schematics of samples for (a) LVI, (b) M1D, (c) FAI and (d) FAD

ination and $5,10,15,20$ were the delamination lengths in $5,10,15,20 \mathrm{~mm}$

\subsection{Characterization}

Microchanneled carbon-epoxy samples were infused with SHA with help of vacuum and both ends of microchannels were sealed using commercially available quick-set steel-putty, before they were subjected to LVI drop-weight and mode-I delamination test.

Impact damage was induced by dropping a steel hammer of weight $4.62 \pm 0.12 \mathrm{~kg}$ with $12 \pm 0.1 \mathrm{~mm}$ punch diameter from varying heights on the flat surface of each sample with rubber pad supported back face. The weight was dropped from variable heights to get four specific impact energies (4.62, $6.93,9.24$ and $11.55 \mathrm{~J}$ ) which resulted in impact damage of variable intensities in separate sets of samples. These impact energies were carefully selected so as to induce only slight damage in embedded microchannels (to release SHA) and composite samples and not to cause the complete failure of composite samples.

M1D damage was generated by applying a tensile load to the piano hinges bonded to each sample. Mode-I tests were carried out on a tensile testing machine (CMT-5105, SANS, China) at $1.5 \mathrm{~mm} \cdot \mathrm{min}^{-1}$ crosshead speed. The growth of M1D front was observed visually and tests were terminated after producing four specific mode-I delaminations $(5,10,15$ and $20 \mathrm{~mm})$ in four different sets of samples. The mode-I delaminations lengths were selected in such a manner that they hit the circular edge of microchannels (to release SHA).
Upon impact and delamination damage, the SHA in the microchannels was released to fill the damage and the samples were allowed to self-heal. The subsequent flexural testing was performed to investigate the efficiency of self-healing for LVI and M1D damage. Four-point bending tests were also carried out on CMT5105 testing machine using test fixtures, as described in ASTM D6272 [38]. The support spans were kept at 32 and $64 \mathrm{~mm}$ and crosshead speed was set as $2 \mathrm{~mm} \cdot \mathrm{min}^{-1}$. The average value of the flexural strength was calculated by five individual measurements

Surface morphologies of the LVI, M1D damaged, FAI, FAD and healed samples were characterized by scanning electron microscope (SEM, Hitachi SU8010, Japan).

\section{Results and discussion}

\subsection{Impact damage}

The damage that appeared on the impact face surface of each sample by LVI with energies 4.62, 6.93, 9.24 and $11.55 \mathrm{~J}$ was roughly elliptical and is shown in Figure 3. The minor axis of the impression was aligned with the long axis of the samples due to higher bending stiffness of the laminate in this direction. No significant difference in impact damage was found between three groups of microchanneled carbon-epoxy samples, with (I) microchannels, (II) SHAfilled microchannels and (III) healed samples.

\subsection{Delamination damage}

The mode-I delamination damage produced was rectangular in shape and located at the mid-plane of the sample with no visible damage onto the front or back 


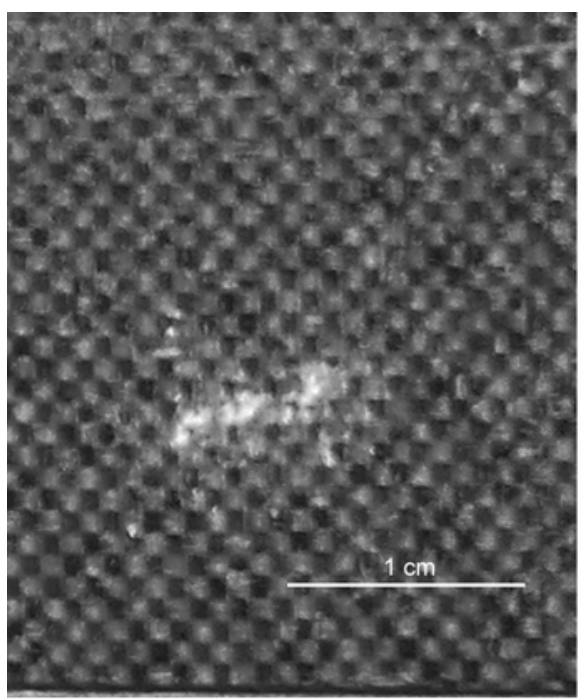

a)

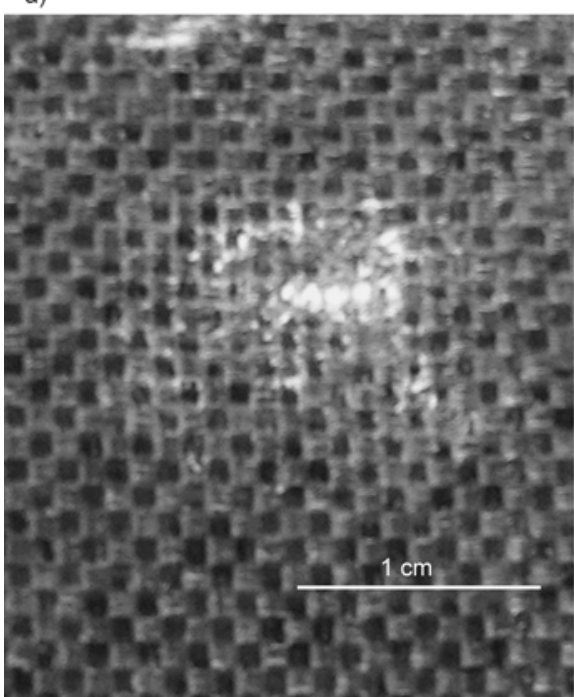

c)

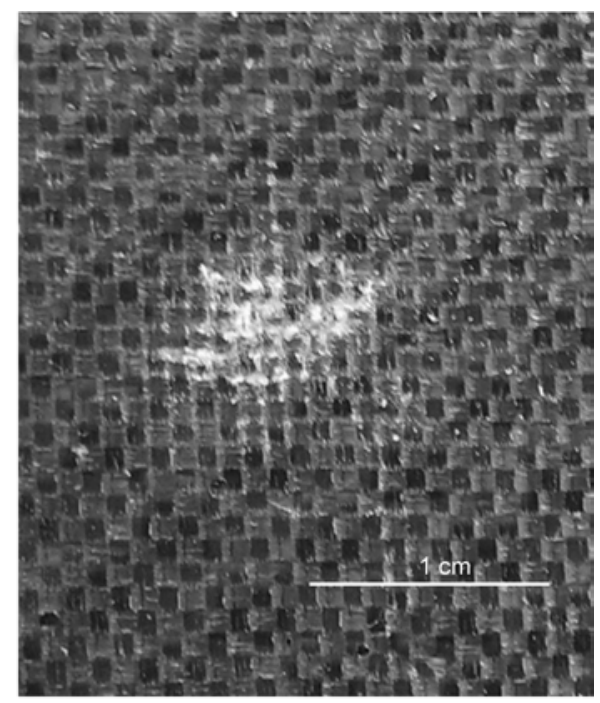

b)

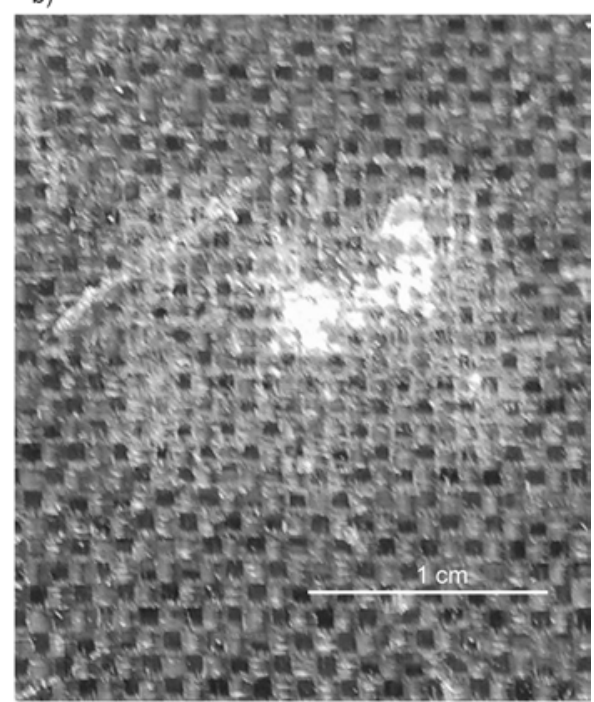

d)

Figure 3. Digital photographs of impact damage at the impact face of microchanneled carbon- epoxy samples due to impact energy (a) $4.62 \mathrm{~J}$, (b) $6.93 \mathrm{~J}$, (c) $9.24 \mathrm{~J}$ and (d) $11.55 \mathrm{~J}$

surface of the laminate. The length of the delamination was aligned with the long axis of the sample. No significant damage was observed on the fiber's surface and the delamination was caused only due to failure of matrix. The mode-I delamination damage in assorted samples is presented in Figure 4.

\subsection{Four-point-flexural strength}

The four-point-flexural strength of undamaged, LVI damaged, M1D damaged and healed microchanneled carbon-epoxy composites were calculated using the following Equation (1) as described in ASTM D6272 [38]:

$$
\sigma=\frac{3 P L}{4 b d^{2}}
$$

where $\sigma$ is the flexural strength [MPa], $P$ is the load $[\mathrm{N}], L$ is the support span [mm], $b$ is the width of sample [mm] and $d$ is the depth of sample [mm]. The healing efficiency [39] was calculated by Equations (2) and (3):

$$
\begin{aligned}
& \eta_{\text {FAI }}=\frac{\sigma^{\text {Healed }}}{\sigma^{\text {Undamaged }}} \cdot 100 \\
& \eta_{\text {FAD }}=\frac{\sigma^{\text {Healed }}}{\sigma^{\text {Undamaged }}} \cdot 100
\end{aligned}
$$

where $\sigma^{\text {Healed }}$ is the flexural strength of the healed sample after impact/delamination damage and $\sigma^{\text {Undamaged }}$ is the flexural strength of undamaged sample. The four-point-flexural strength of undamaged, LVI damaged, M1D damaged and healed microchan- 


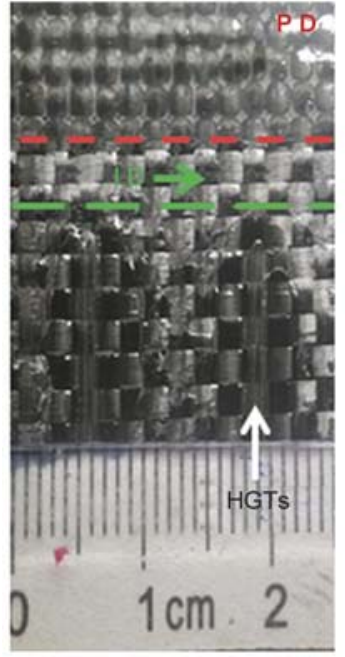

a)

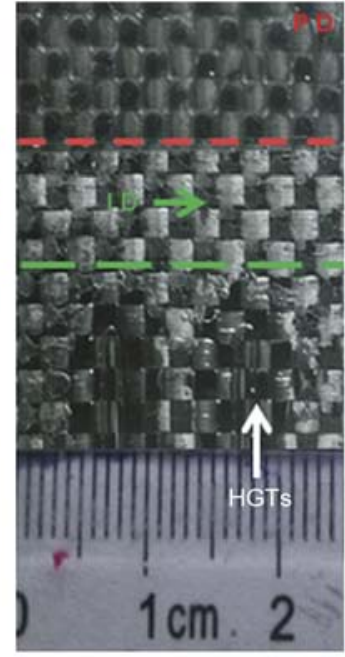

b)

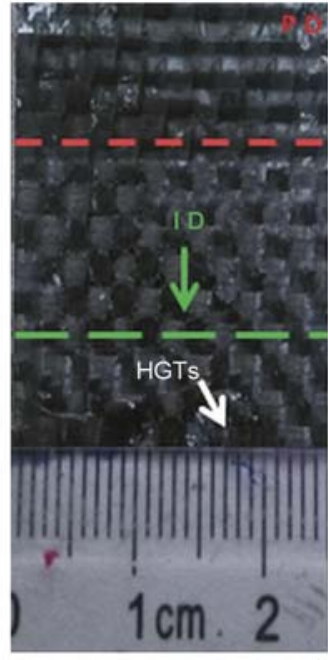

c)

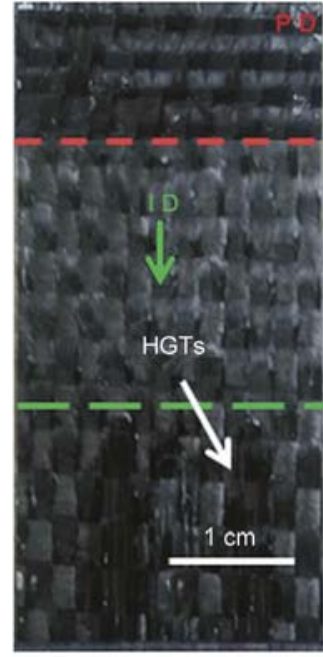

d)

Figure 4. Digital photographs of delamination damage at the mid-plane of microchanneled carbon-epoxy samples with mode-I delamination length (a) $5 \mathrm{~mm}$, (b) $10 \mathrm{~mm}$, (c) $15 \mathrm{~mm}$, (d) $20 \mathrm{~mm}$, where 'PD' is prefabricated delamination and 'ID' is induced delamination

neled carbon-epoxy composites are summarized in Figure 5.

\subsection{Effect of LVI damage on flexural strength} The LVI with impact energies in the range of (4.62$11.55 \mathrm{~J})$ reduced the flexural strength of microchanneled carbon- epoxy composites. It is clear from Figure 5 that the loss in flexural strength due to LVI increased steadily with impact energies. The amount of energy absorbed due to $11.55 \mathrm{~J}$ (impact energy) was approximately 3 times higher than the energy absorbed due to $4.62 \mathrm{~J}$, so was its effect. The flexural strength decreased $16.77 \%$ due to $4.62 \mathrm{~J}$ and $28.69 \%$ due to $11.55 \mathrm{~J}$, which was almost twice than due to $4.62 \mathrm{~J}$. This decrease in flexural strength due to LVI was directly related to the breakage of carbon

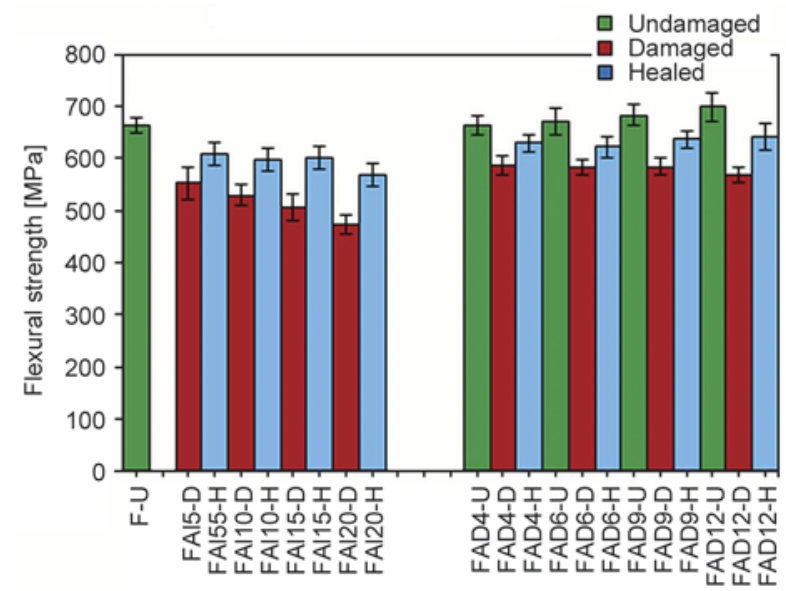

Figure 5. Flexural strength of undamaged, LVI damaged, M1D damaged and healed microchanneled carbon-epoxy composites fibers in the damage region and widely spread matrix cracks and delaminations, shown in the SEM micrograph in Figure 6, obtained from the region of LVI of microchanneled composite sample.

\subsection{Effect of LVI damage on flexural failure}

When a four-point-bending load was applied to a LVI damaged microchanneled carbon-epoxy composite sample, initially it was taken-up by top ply carbon fibers, but subsequently it was shifted to the remaining plies through fiber/ resin interface. With increasing load the sample started bending, but the ruptured fibers and matrix microcracks (Figure 6) at the LVI damaged zone acted as stress concentration points and caused the sample to fail at much lower loading value. Final failure of the sample occurred

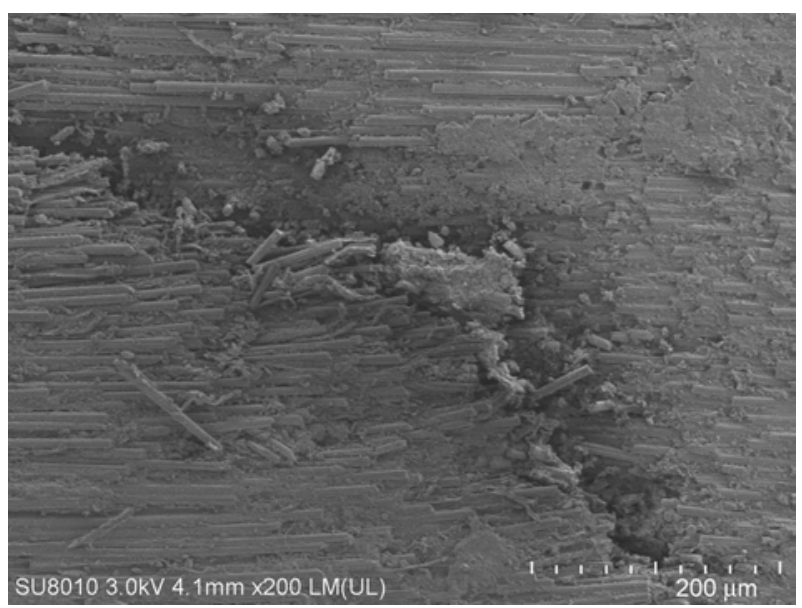

Figure 6. SEM micrograph of LVI damaged microchanneled carbon-epoxy composite sample, showing fiber damage and matrix microcracks in the impact region 


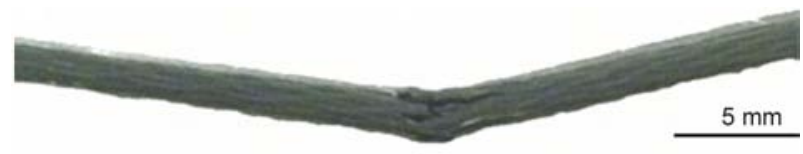

Figure 7. Digital photograph of FAI failed microchanneled carbon-epoxy composite sample

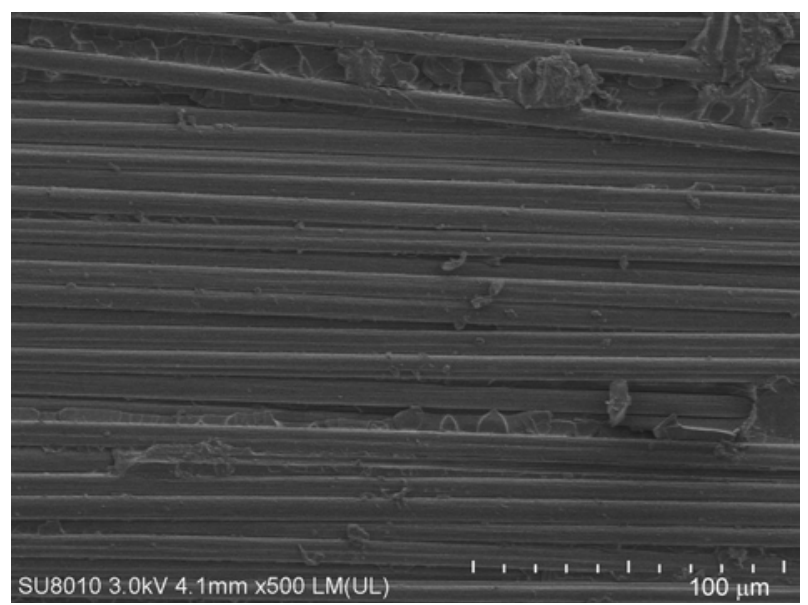

Figure 8. SEM micrographs of Four-point-bend flexural failure of LVI damaged microchanneled carbonepoxy composite sample before healing, showing interlaminar shear marks; Hackles

with the breakage of top ply carbon fibers under compression and bottom ply carbon fibers under tension (Figure 7).

In addition to breakage of carbon fibers of top and bottom plies a very minute shearing among laminate plies was also found during SEM of the FAI failed microchanneled carbon-epoxy composite samples, as shown in the SEM micrograph in Figure 8.

\subsection{Restoration of flexural strength after LVI}

The flexural strength of microchanneled carbonepoxy composites which were not subjected to any

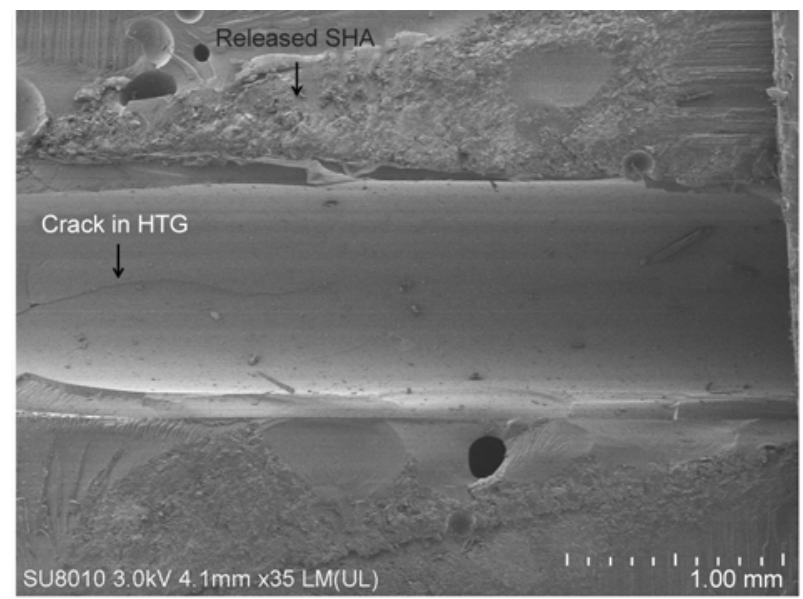

a) external damage (LVI) was $663.85 \mathrm{MPa}$. However, when these samples were subjected to LVI, the impact energy penetrated into the composite sample and ruptured some fibers at the point of impact along with some microcracks and delaminations in matrix (shown in Figure 6). Furthermore, the LVI also produced fissures in the SHA-filled HGTs and caused the SHA to release, reach the damage zone and fill the microcracks. This release of SHA through cracked HGT is shown in Figure 9a and healing by SHA is shown in Figure 9b.

Figure 9 contains the SEM micrographs of the fracture surfaces, obtained from the region of LVI and four-point-bend flexural failed sample after healing. After 48 hours at room temperature, SHA was fully cured and caused the LVI damage samples to restore their flexural strength $(\sim 90 \%)$. This healing behavior of LVI-damaged microchanneled carbon-epoxy composite sample is presented in Figure 10.

Figure 11 presents the healing efficiencies of microchanneled carbon-epoxy composite samples dam-

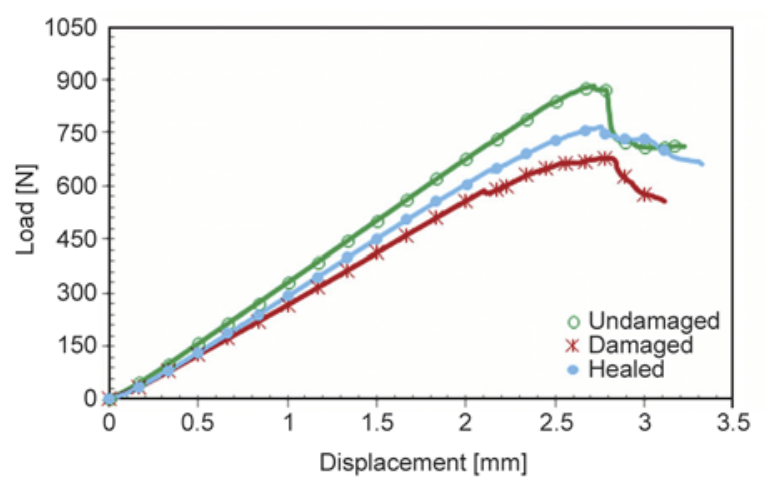

Figure 10. Representative load-displacement curves of undamaged, LVI-damaged (9.24 J) and healed carbon-epoxy composites samples by flexural testing

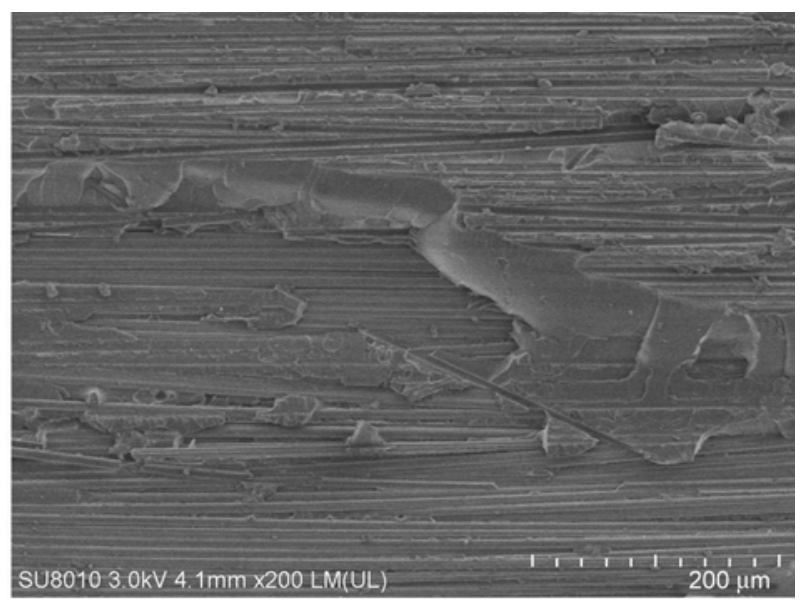

b)

Figure 9. SEM micrographs of LVI-damaged microchanneled carbon-epoxy composite samples after healing (a) showing crack in HGT and release of SHA and (b) showing healing by SHA 


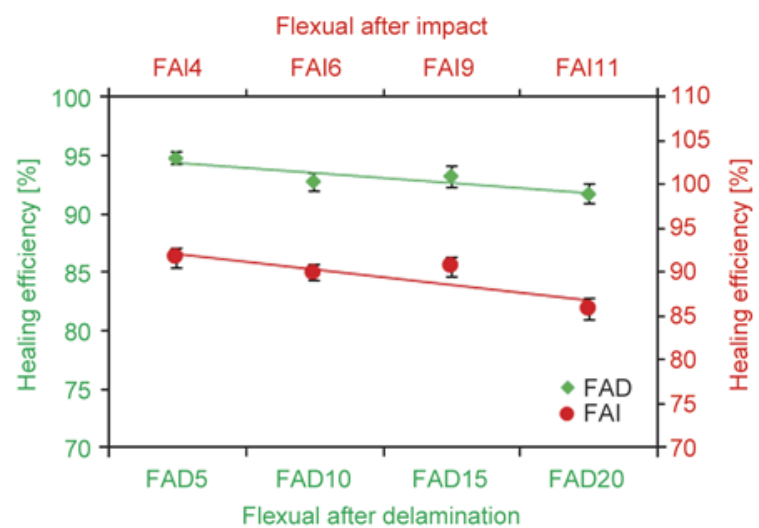

Figure 11. Healing efficiency of carbon-epoxy composites after LVI and M1D damage

aged by a range of LVI. It was observed that the healing and restoration of flexural strength was higher for LVI with smaller impact energies and vice versa. This was because of the reason that the higher impact energies caused greater damage with dense network of microcracks, which could not be completely filled by SHA due to its higher viscosity.

\subsection{Effect of healing on the failure of FAI}

As the healing mechanism involved the release of liquid SHA to the damage region, which filled the microcracks in the matrix phase and restored the flexural strength upon curing. In case of LVI, carbon fibers were also damaged along with resin and SHA only repaired the microcracks in resin not fibers. Hence, damage in terms of ruptured fibers remained there, also not all the microcracks were fully repaired. So, when LVI-damaged-healed samples were flexural loaded, the LVI damage zone still acted as stress concentration point and caused the healed-samples (Figure 12) to fail in a similar way as that of un-healed samples (Figure 7). Hence, healing did not significantly affect the failure behavior of FAI samples.

\subsection{Effect of M1D damage on flexural strength}

Effect of a series of M1D damage on the flexural strength of microchanneled carbon-epoxy composites was similar to the effect of LVI damage, but different in magnitude. $5 \mathrm{~mm}$ long M1D caused 11\%

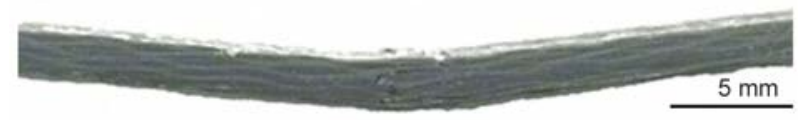

Figure 12. Digital photograph of healed-FAI failed microchanneled carbon-epoxy composite sample

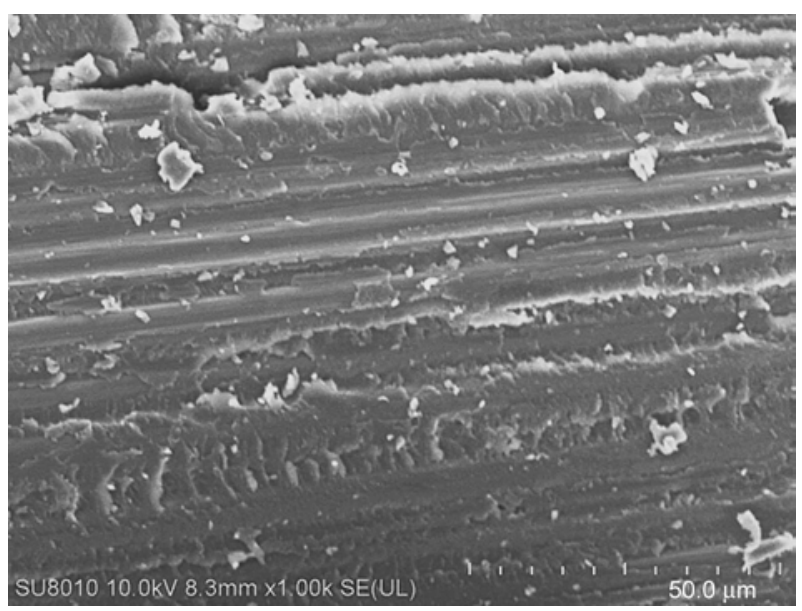

Figure 13. SEM micrographs of M1D damaged microchanneled carbon-epoxy composite sample before healing, showing mode-I delamination failure; River Pattern

decrease in the flexural strength of microchanneled carbon-epoxy composites that increased linearly with increase in M1D length (Figure 5). Figure 5 showed that the highest fall in flexural strength (20\%) was due to presence of $20 \mathrm{~mm}$ long M1D. This loss was caused mainly due to the separation of layers by M1D. The applied load peeled the sample by ripping the resin not fibers, as the applied load was out of the plane of fiber plies. This breaking of resin in the opening tensile mode, left special marks in resin, known as river pattern, which can be seen in Figure 13.

SEM micrograph of the fracture surface of M1D damage region before healing is presented in Figure 13. Carbon fibers were found intact; their surfaces were smooth with no visible fiber breakage or damage. Hence, the M1D caused failure in matrix phase only. It can also be observed that loss of flexural strength after LVI damage was higher than the loss of flexural strength after M1D. This difference was found due to the type of damage both produced in the host laminate. LVI produced diverse type of damage that affected both fiber and matrix phases in all layers (Figure 6) with highest damage on the top ply (impact face) and lowest on the bottom layer (nonimpact face). While M1D damaged only the midplane and mainly in the matrix phase without any fiber damage (Figure 13).

\subsection{Effect of M1D damage on flexural failure}

Similarly, on application of four-point-bending load on a microchanneled carbon-epoxy composite sample with induced M1D damage, it was taken by top 


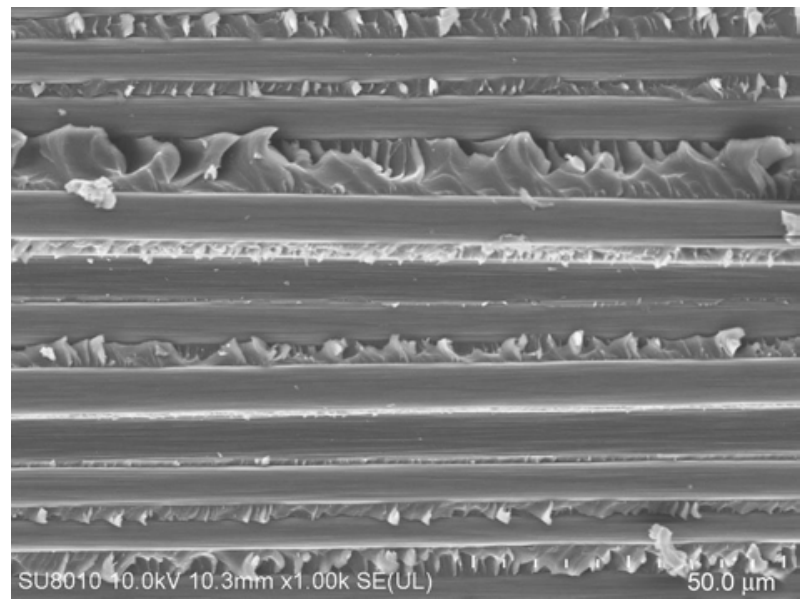

Figure 14. SEM micrograph of four-point-bend flexural failed after M1D damaged microchanneled carbon-epoxy composite sample before healing, showing significant interlaminar shear marks; Hackles

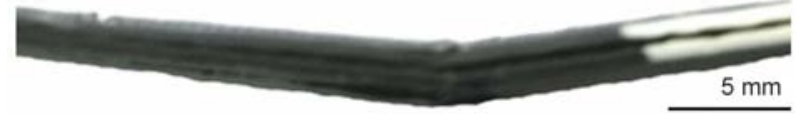

Figure 15. Digital photograph of healed-FAD failed microchanneled carbon-epoxy composite sample

ply first which was successively transferred to the remaining plies through fiber/resin interface. As the load increased, the sample started bending, but at the same time the delamination crack in the sample propagated and caused some slippage among carbon fiber layers. This slippage was the interlaminar shear that appeared as hackles in resin, which can be seen in SEM micrographs of Figure 14.

It was also noted that as the induced M1D damage increased, so was the interlaminar shearing among carbon fiber layers. However, final failure of the sample occurred with the breakage of top ply carbon fibers under compression and bottom ply under tension (Figure 15) i.e. similar to LVI damaged samples but with significant amount of shearing among laminate plies, which depended upon the induced M1D length.

\subsection{Restoration of flexural strength after M1D}

The flexural strength of undamaged microchanneled carbon-epoxy composites with HGTs of lengths $75,70,65$ and $60 \mathrm{~mm}$ were $665.01,671.49,683.33$ and 699.16 MPa respectively. In order to induce M1D damage, these samples were mode-I tensile loaded, which separated the layers by damaging the resin not fibers (Figure 13). Likewise, the lengths of M1D

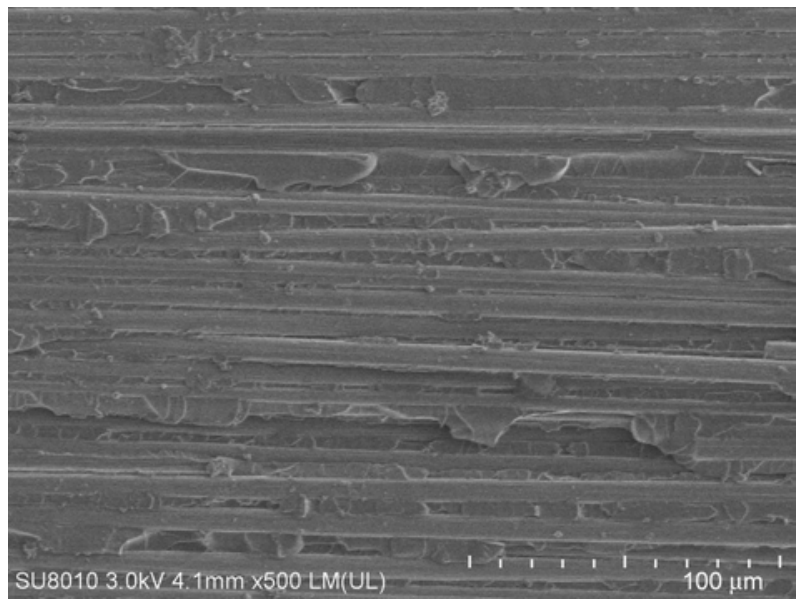

Figure 16. SEM micrographs of M1D damaged microchanneled carbon-epoxy composite sample after healing, showing release and filling of damage by SHA

were such selected that the delamination crack struck the circular edge of SHA-filled HGTs to release the SHA and fill the damage zone. This release of SHA and filling of delamination crack is shown in Figure 16. After release and fill of SHA, each sample was left for curing for 48 hours at room temperature. This curing of SHA re-bonded the detached layers and repaired the M1D damage and restored the flexural strength ( $93 \%)$.

Similar to LVI damaged samples, healing and restoration of flexural strength after M1D damage was higher for smaller delamination lengths and lower for bigger delamination lengths (as shown in Figure 11). The reason for this analogous behavior was believed to be the same, i.e. viscosity build-up (with time) of resin limited the filling of larger M1D damage. This healing behavior of M1D-damaged microchanneled carbon-epoxy composite sample is presented in Figure 17.

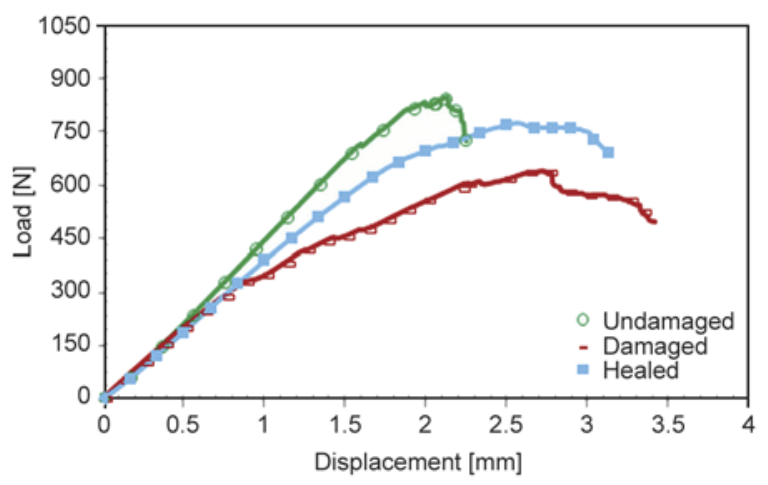

Figure 17. Representative load-displacement curves of undamaged, M1D-damaged $(15 \mathrm{~mm})$ and healed carbon-epoxy composites samples by flexural testing 


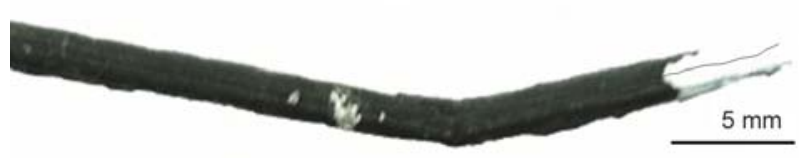

Figure 18. Digital photograph of healed-FAD failed microchanneled carbon-epoxy composite sample

\subsection{Effect of healing on the failure of FAD}

In comparison to impact, delamination occurred only in the matrix phase, which was comprehensively repaired by the action of SHA. So, when a flexural load was applied to M1D damaged-healed samples, they failed with the breakage of top and bottom plies carbon fibers (Figure 18) and a very minute shearing among plies due to absence of any starter delamination crack. Hence, healing significantly affected the failure behavior of FAD samples. The main difference was the amount of interlaminar shearing.

\section{Conclusions}

A biomimetic approach was used to develop and demonstrate a self-repairing capability of carbonepoxy composites, which proved to be an efficient way to recover flexural strength after a range of LVI and M1D damage events. Damage produced by LVI was diverse that consisted of locally damaged fibers and widespread matrix microcracks, whereas M1D damage was limited to mid-plane and matrix phase only. Due to this reason LVI damage caused more loss in flexural strength and less healing efficiency than the M1D damage. The loss in flexural strength increased linearly with impact energy and delamination length. However, healing efficiency was found to decrease with increase in impact and delamination damage, which was believed to be due to inaccessibility of SHA to some microcracks as a consequence of its viscosity build-up with time. Failure of FAI and FAD samples were significantly different. FAI samples failed due to fiber breakage in the LVI region, while FAD samples failed due to interlaminar shearing in the delamination region and fiber breakage in the center of sample.

\section{Acknowledgements}

The authors would like to acknowledge the funding provided by NUAA Fundamental Research Funds (NO.NS2015060) and Jiangsu collaborative innovation center for advanced inorganic functional composites.

\section{References}

[1] Richardson M. O. W., Wisheart M. J.: Review of lowvelocity impact properties of composite materials. Composites Part A: Applied Science and Manufacturing, 27, 1123-1131 (1996). DOI: $10.1016 / 1359-835 X(96) 00074-7$

[2] Saeed M. U., Chen Z., Chen Z., Li B.: Compression behavior of laminated composites subjected to damage induced by low velocity impact and drilling. Composites Part B: Engineering, 56, 815-820 (2014). DOI: $10.1016 /$ j.compositesb.2013.09.017

[3] Amaro A. M., Reis P. N. B., de Moura M. F. S. F.: Delamination effect on bending behaviour in carbon-epoxy composites. Strain, 47, 203-208 (2011). DOI: $10.1111 / \mathrm{j} .1475-1305.2008 .00520 . x$

[4] Ye L., Lu Y., Su Z., Meng G.: Functionalized composite structures for new generation airframes: A review. Composites Science and Technology, 65, 1436-1446 (2005). DOI: 10.1016/j.compscitech.2004.12.015

[5] Heida J. H., Platenkamp D. J.: In-service inspection guidelines for composite aerospace structures. in ' $18^{\text {th }}$ World Conference on Nondestructive Testing. Durban, South Africa' p.14 (2012).

[6] Wu D. Y., Meure S., Solomon D.: Self-healing polymeric materials: A review of recent developments. Progress in Polymer Science, 33, 479-522 (2008).

DOI: 10.1016/j.progpolymsci.2008.02.001

[7] Murphy E. B., Wudl F.: The world of smart healable materials. Progress in Polymer Science, 35, 223-251 (2010).

DOI: 10.1016/j.progpolymsci.2009.10.006

[8] Yuan Y. C., Yin T., Rong M. Z., Zhang M. Q.: Self healing in polymers and polymer composites. Concepts, realization and outlook: A review. Express Polymer Letters, 2, 238-250 (2008). DOI: $10.3144 /$ expresspolymlett.2008.29

[9] Murphy E. B., Bolanos E., Schaffner-Hamann C., Wudl F., Nutt S. R., Auad M. L.: Synthesis and characterization of a single-component thermally remendable polymer network: Staudinger and stille revisited. Macromolecules, 41, 5203-5209 (2008).

DOI: $10.1021 / \mathrm{ma} 800432 \mathrm{~g}$

[10] Pingkarawat K., Mouritz A. P.: Stitched mendable composites: Balancing healing performance against mechanical performance. Composite Structures, 123, 54-64 (2015).

DOI: $10.1016 /$ j.compstruct.2014.12.034

[11] Wang C. H., Sidhu K., Yang T., Zhang J., Shanks R.: Interlayer self-healing and toughening of carbon fibre/ epoxy composites using copolymer films. Composites Part A: Applied Science and Manufacturing, 43, 512518 (2012).

DOI: $10.1016 /$ j.compositesa.2011.11.020

[12] Brown E. N., White S. R., Sottos N. R.: Microcapsule induced toughening in a self-healing polymer composite. Journal of Materials Science, 39, 1703-1710 (2004). DOI: 10.1023/B:JMSC.0000016173.73733.dc 
[13] Yin T., Rong M. Z., Wu J., Chen H., Zhang M. Q.: Healing of impact damage in woven glass fabric reinforced epoxy composites. Composites Part A: Applied Science and Manufacturing, 39, 1479-1487 (2008).

DOI: $10.1016 /$ j.compositesa.2008.05.010

[14] Patel A. J., Sottos N. R., Wetzel E. D., White S. R.: Autonomic healing of low-velocity impact damage in fiberreinforced composites. Composites Part A: Applied Science and Manufacturing, 41, 360-368 (2010). DOI: 10.1016/j.compositesa.2009.11.002

[15] Yuan Y. C., Ye Y., Rong M. Z., Chen H. B., Wu J., Zhang M. Q., Qin S. X., Yang G. C.: Self-healing of lowvelocity impact damage in glass fabric/epoxy composites using an epoxy-mercaptan healing agent. Smart Materials and Structures, 20, 015024/1-015024/12 (2011).

DOI: $10.1088 / 0964-1726 / 20 / 1 / 015024$

[16] Hamilton A. R., Sottos N. R., White S. R.: Pressurized vascular systems for self-healing materials. Journal of the Royal Society Interface, 9, 1020-1028 (2012).

DOI: $10.1098 /$ rsif.2011.0508

[17] Bond I. P., Trask R. S., Williams R.: Self-healing fiberreinforced polymer composites. MRS Bulletin, 33, 770774 (2008).

[18] Pang J. W. C., Bond I. P.: A hollow fibre reinforced polymer composite encompassing self-healing and enhanced damage visibility. Composites Science and Technology, 65, 1791-1799 (2005).

DOI: $10.1016 /$ j.compscitech.2005.03.008

[19] Roach D.: Real time crack detection using mountable comparative vacuum monitoring sensors. Smart Structures and Systems, 5, 317-328 (2009).

DOI: $10.12989 /$ sss.2009.5.4.317

[20] Pang J. W. C., Bond I. P.: 'Bleeding composites' damage detection and self-repair using a biomimetic approach. Composites Part A: Applied Science and Manufacturing, 36, 183-188 (2005).

DOI: 10.1016/j.compositesa.2004.06.016

[21] Soghrati S., Thakre P. R., White S. R., Sottos N. R., Geubelle P. H.: Computational modeling and design of actively-cooled microvascular materials. International Journal of Heat and Mass Transfer, 55, 5309-5321 (2012).

DOI: 10.1016/j.ijheatmasstransfer.2012.05.041

[22] Toohey K. S., Hansen C. J., Lewis J. A., White S. R., Sottos N. R.: Delivery of two-part self-healing chemistry via microvascular networks. Advanced Functional Materials, 19, 1399-1405 (2009).

DOI: $10.1002 / \mathrm{adfm} .200801824$

[23] Hansen C. J., Wu W., Toohey K. S., White S. R., Sottos N. R., Lewis J. A.: Self-healing materials with interpenetrating microvascular networks. Advanced Materials, 21, 4143-4147 (2009).

DOI: $10.1002 / \mathrm{adma} .200900588$
[24] Norris C. J., White J. A. P., McCombe G., Chatterjee P., Bond I. P., Trask R. S.: Autonomous stimulus triggered self-healing in smart structural composites. Smart Materials and Structures, 21, 1-10 (2012). DOI: 10.1088/0964-1726/21/9/094027

[25] Hansen C. J., White S. R., Sottos N. R., Lewis J. A.: Accelerated self-healing via ternary interpenetrating microvascular networks. Advanced Functional Materials, 21, 4320-4326 (2011).

DOI: $10.1002 / \mathrm{adfm} .201101553$

[26] Saeed M-U., Chen Z., Li B.: Manufacturing strategies for microvascular polymeric composites: A review. Composites Part A: Applied Science and Manufacturing, 78, 327-340 (2015).

DOI: 10.1016/j.compositesa.2015.08.028

[27] Bleay S. M., Loader C. B., Hawyes V. J., Humberstone L., Curtis P. T.: A smart repair system for polymer matrix composites. Composites Part A: Applied Science and Manufacturing, 32, 1767-1776 (2001).

DOI: $10.1016 / \mathrm{S} 1359-835 \mathrm{X}(01) 00020-3$

[28] Trask R. S., Williams G. J., Bond I. P.: Bioinspired self-healing of advanced composite structures using hollow glass fibres. Journal of the Royal Society Interface, 4, 363-371 (2007).

DOI: $10.1098 /$ rsif.2006.0194

[29] Williams G., Trask R., Bond I.: A self-healing carbon fibre reinforced polymer for aerospace applications. Composites Part A: Applied Science and Manufacturing, 38, 1525-1532 (2007).

DOI: 10.1016/j.compositesa.2007.01.013

[30] Williams G. J., Bond I. P., Trask R. S.: Compression after impact assessment of self-healing CFRP. Composites Part A: Applied Science and Manufacturing, 40, 1399-1406 (2009).

DOI: 10.1016/j.compositesa.2008.05.021

[31] Zainuddin S., Arefin T., Fahim A., Hosur M. V., Tyson J. D., Kumar A., Trovillion J., Jeelani S.: Recovery and improvement in low-velocity impact properties of eglass/epoxy composites through novel self-healing technique. Composite Structures, 108, 277-286 (2014). DOI: 10.1016/j.compstruct.2013.09.023

[32] Yue H-B., Fernández-Blázquez J. P., Beneito D. F., Vilatela J. J.: Real time monitoring of click chemistry self-healing in polymer composites. Journal of Materials Chemistry A, 2, 3881-3887 (2014).

DOI: $10.1039 / \mathrm{C} 3 \mathrm{TA} 14961 \mathrm{G}$

[33] Kling S., Czigány T.: Damage detection and self-repair in hollow glass fiber fabric-reinforced epoxy composites via fiber filling. Composites Science and Technology, 99, 82-88 (2014).

DOI: $10.1016 /$ j.compscitech.2014.05.020

[34] Kessler M. R., White S. R.: Self-activated healing of delamination damage in woven composites. Composites Part A: Applied Science and Manufacturing, 32, 683-699 (2001).

DOI: $10.1016 / \mathrm{S} 1359-835 \mathrm{X}(00) 00149-4$ 
[35] Kessler M. R., Sottos N. R., White S. R.: Self-healing structural composite materials. Composites Part A: Applied Science and Manufacturing, 34, 743-753 (2003).

DOI: $10.1016 / \mathrm{S} 1359-835 X(03) 00138-6$

[36] Patrick J. F., Hart K. R., Krull B. P., Diesendruck C. E., Moore J. S., White S. R., Sottos N. R.: Continuous selfhealing life cycle in vascularized structural composites. Advanced Materials, 26, 4302-4308 (2014).

DOI: 10.1002/adma.201400248

[37] ASTM Standard D5528-01: Standard test method for mode I interlaminar fracture toughness of unidirectional fiber-reinforced polymer matrix composites (2007).
[38] ASTM Standard D 6272-02, Standard test method for flexural properties of unreinforced and reinforced plastics and electrical insulating materials by fourpoint bending (2002).

[39] Brown E. N.: Use of the tapered double-cantilever beam geometry for fracture toughness measurements and its application to the quantification of self-healing. Journal of Strain Analysis for Engineering Design, 46, 167-186 (2011).

DOI: $10.1177 / 0309324710396018$ 